\title{
EDITORIAL
}

\section{How Can We Afford to Save Our Children from Pneumonia - The Biggest Killer !}

Pneumonia - the leading killer ${ }^{1,2}$ still claims $>29 \% 0^{1}$ (including 10\% neonatal death) of world's under five (U-5) annual deaths ${ }^{2-4}$ totaling to $\sim 3$ million, ${ }^{1}$ despite advances in the understanding of patho-physiology of child death. ${ }^{5}$ Pneumonia alone kills more children than combined deaths due to AIDS, malaria, tuberculosis and measles. ${ }^{1,6}$

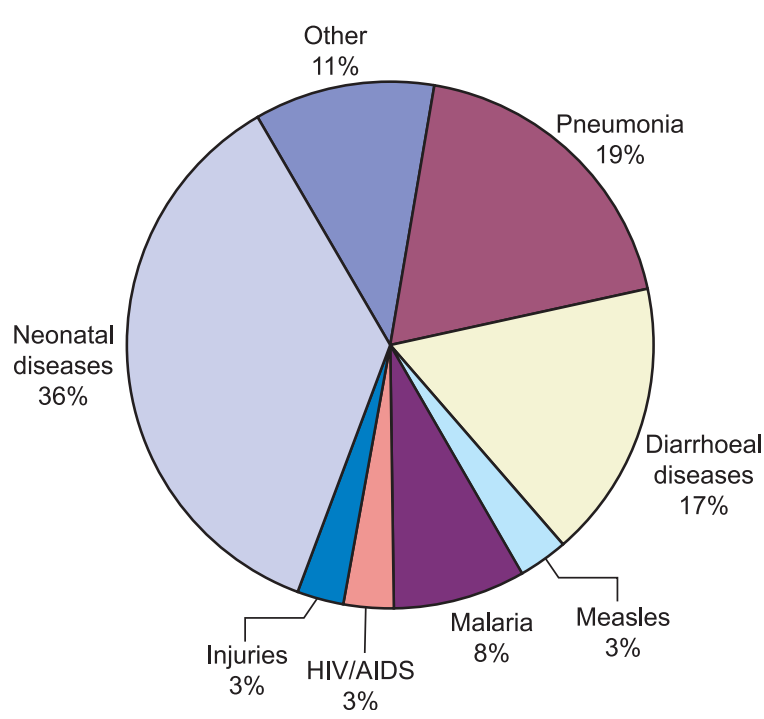

Major causes of global under five mortality.

Source: WHO. World Health Statistics, 2007

Extensive activities took place on international health over the past decade ${ }^{6}$ focusing renewed attention and possible interventions to reduce global burden of U-5 mortality and morbidity. ${ }^{5}$ But, pneumonia remains neglected $^{1}$ with a little attention paid on to $\mathrm{it}^{1,6}$ including essential research and vaccine trials. ${ }^{7}$ As a result, worldwide U-5 pneumonia death still persists to be unacceptably high $^{3}$ particularly in least developed countries (LDC). ${ }^{2}$ Global estimation revealed 150 million pneumonia episodes/year among U-5 children in developing countries, accounting for $>95 \%$ of all new cases worldwide, 11 to 20 million of which require hospitalization. ${ }^{8}$ Around $19 \% \%^{3-4}$ of these occur in mere 42 developing nations ${ }^{5}$ and remains the highest in South-East Asia region $(\mathrm{SEAR}){ }^{5,9}$

\section{Causes of Child Mortality in South East Asia Region}

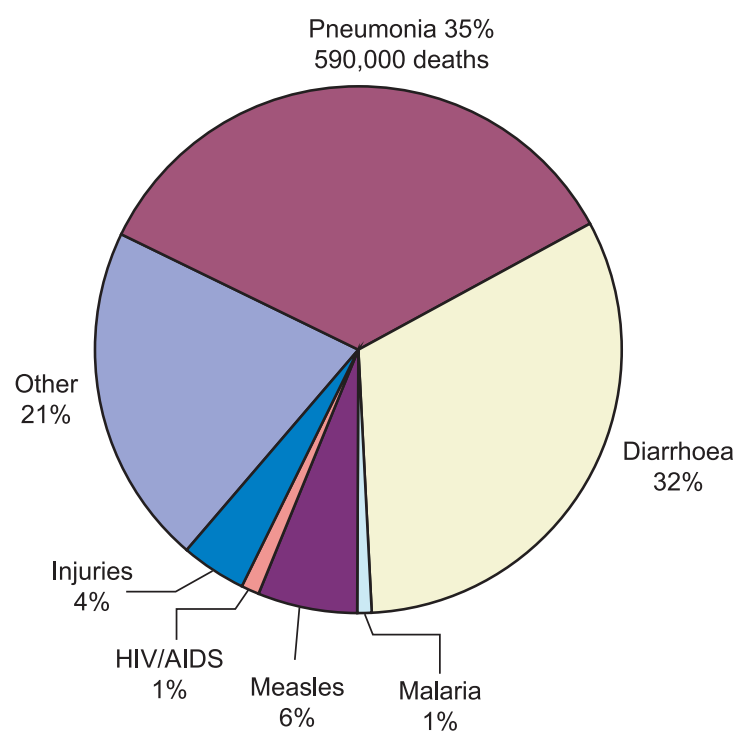

Total average annual child deaths: $1,709,000$

Average annual mortality for children under 5 years excluding neonatal deaths, 2000-03

While south Asian and sub-Sahara countries bear the burden of $>$ half $^{8}$ of total U-5 pneumonia episode worldwide; $3 / 4^{\text {th }}$ of these occur in mere 15 countries $^{8}$ - where Bangladesh ranks $4^{\text {th }}$ with 6 million pneumonia cases. ${ }^{1,8}$ Incidence of ALRI (mostly pneumonia) related hospital admission among U-5 in rural Bangladesh is 50.2 /child-year-observed. ${ }^{10}$ Interestingly, U-5 mortality in Bangladesh though came down from 150 in 1965 to 68 in $2007,11-12$ pneumonia incidence still remains very high ${ }^{13}(47 \%$ of U-5 illness $\left.{ }^{14}\right)$ including deaths $\left(23 \%{ }^{15,16}\right)$ which may escalate even more if neonatal pneumonia death of $\sim 10 \%$ is added. ${ }^{14-16}$ Pneumonia due to Strept. pneumoniae alone kills 1 million U-5 children annually, ${ }^{17}$ mojority being among $<2$ years children of LDC, as WHO estimated recently. ${ }^{16,17}$ 
There are several risk factors for high pneumonia incidence. Undernourished and Immuno-deficient 18 children, particularly who are not-exclusively breastfed remain at constant risk of developing pneumonia. Poor environment, indoor air pollution, overcrowding etc. may also play a role. Few other diseases also enhance the risk of pneumonia; like measles, ${ }^{19-20}$ whooping cough, ${ }^{20}$ etc., that are almost guarded by satisfactory EPI coverage.

It is difficult to identify a pathogen responsible for pneumonia death as most of the cases are not bacteremic and blood culture is insensitive. However, the innovative use of vaccine as a probe, showed that infection caused by Streptococcus pneumoniae (Pneumococcus) 1,7,21 and Haemophilus influenzae type $\mathrm{b}$ (Hib) ${ }^{16,22-25}$ are the major causes of fatal childhood pneumonia which accounts for about $50 \%$ and $25 \%$, respectively.

So, this emerging problem needs urgent attention towards its prevention and treatment in following two ways: first, proper case management with appropriate antibiotic therapy; and second, prevention by immunization with suitable vaccines. As appropriate vaccines are yet to be made available in 3rd world countries, Government of Bangladesh (GOB) has adopted programs like Acute Respiratory Illness (ARI) Control Program and subsequently Integrated Management of Childhood Illness (IMCI), developed by WHO and UNICEF, in creating awareness among the doctors, community health workers and care givers. The awareness mainly aimed at early case detection, quick referral and providing appropriate treatment. These activities also extended upto family level to empower the caregivers with sufficient knowledge in addressing common problems and deciding when to transport the child to a health care facility with more extensive supervised care. These measures proved to have significant impact in reducing U-5 mortality.

Current findings from hospital and community based studies underscored the need for preventive strategies as in adjunct to accurate clinical approach, improved diagnostic tools and perfect treatment regimen. ${ }^{5}$ But these may hamper due to lack in gold standard in current algorithms (insufficient specificity) and lack in classic microbiological methods (poor sensitivity). ${ }^{5}$ It is also essential to combine vaccines with particular emphasis on appropriate use of antibiotics in pneumonia prevention programs. $5,26,27$ Meanwhile, Hib-vaccine trial conducted in different countries has shown considerable reduction in pneumonia incidence. GOB has recently introduced Global Alliance for Vaccine and Immunization (GAVI) - funded penta-valent vaccine (DPT, Hepatitis-B and Hib) with a target of not only reducing pneumonia deaths but also preventing $\sim 90 \%$ of Hib-meningitis and others. ${ }^{16}$ But, Bangladeshi children will still die of pneumonia due to a major pathogen, Strept. pneumoniae ${ }^{21}$ which remains uncovered to several serotypes. ${ }^{16}$

Thus, in Bangladesh, where care seeking behavior remains poor and access to health care facilities is hard-to-reach, it is imperative that Govt. of Bangladesh should take prompt initiative to introduce pneumococcal vaccine under EPI though its formulation remains challenging as Streptococcus pneumoniae has 90 serotypes having geographically diverse and immunologically distinct characteristics. ${ }^{1,}$, 21-22 Currently available 7-valent pneumococcal vaccine is customized based on the predominant serotypes of industrialized countries. ${ }^{17}$ So, vaccines need to be customized according to our need by gathering further information about circulating invasive pneumococcal serotypes in Bangladesh and neighboring regions to facilitate accurate formulation of next generation pneumococcal vaccine which we expect to be available soon with the active support from GAVI, to help bring down U-5 pneumonia death significantly.

However a huge budgetary involvement in procuring such a vaccine remains a potential constraint. The GOB should seek financial/technical assistance form donors/UN agencies for this approach. However, a new vaccine grant by GAVI is only $\$ 0.30 /$ infant in the birth cohort/year or minimum $\$ 100,000 .^{28} \mathrm{GOB}$ essentially needs a defined strategy, a robust work plan and a strong political will to make such a vaccination procurement project, cost-effective and sustainable.

Anticipating the huge consumption of pneumococcal vaccine in Bangladesh where birth cohort is $\sim 4 \%$, it will be more cost-effective, if the GOB can start manufacturing this vaccine on its own capacity through transfer of technology. At the same time it will exert a positive impact in our national economy through industrialization and thus creating scope of employment, at least in part. 


\section{Acknowledgement:}

Prof Samir Kumar Saha, Professor of Microbiology, Dhaka Shishu Hospital

(J Bangladesh Coll Phys Surg 2009; 27: 1-3)

Md Abid Hossain Mollah'1, Shegufta Rahman², Kazi Selim Anwar ${ }^{3}$

${ }^{1}$ Professor of Pediatrics, Mymensingh Medical College.

${ }^{2}$ FCPS part II student in Pediatrics, BSMMU.

${ }^{3}$ Public Health Specialist \& Microbiologist.

\section{References:}

1. UNICEF/The World Health Organization. Pneumonia: The Forgotten Killer of Children. 2006. www.unicef.org/ publications/index35626.html.

2. Wardlaw T, Salama P, Johansson EW, et al. Pneumonia: the leading killer of children. The Lancet 2006; 368: 1048-50.

3. Bryce J, Boschi-Pinto C, Shibuya K, Black RE. WHO estimates of the causes of death in children. The Lancet 2005; 365: 1147-52.

4. Bryce J. Can the world afford to save the lives of 6 million children each year? The Lancet 2005; 365: 2193-2200.

5. Bhutta ZA. Dealing with childhood pneumonia in developing countries: how can we make a difference? Arch Dis Child 2007; 92: 286-288.

6. Greenwood BM, Weber MW, Mulholland K. Bull World Health Organization July 2007; 85 (7): 502-503.

7. Cutts FT, Zaman SMA, Enwere G, Jaffar S, Levine OS, Okoko JB, et al. Efficacy of nine-valent pneumococcal conjugate vaccine against pnm \& invasive pneumococcal disease in Gambia: randomized, double-blind, placebocontrolled trial. The Lancet 2005; 365: 1139-1146.

8. Rudan I, C. Boschi-Pinto, T. Wardlaw, E White Hohansson and H. Campbell. The global distribution of clinical episodes of Pneumonia in children under five years of age. Bull World Health Organization 2004; 82: 895-903.

9. Bellamy C. Health Environments in Children. Bull World Health Organization 2003; 81: 157.

10. Baqui AH, Rahman M, Zaman K, Arifeen S-El, Chowdhury HR, Begum N, et al. A population based study of hospital admission, incidence rate \& bacterial aetiology of ALRI in children aged less than five years in Bangladesh. $J$ Health Popul Nutr 2007; 25(2): 179-188.

11. Bangladesh Demographic and Health Survey (BDHS), 2007.

12. UNICEF. State of World Children, 2007.

13. Brooks WA, Santosham M, Naheed A, Goswami D, Wahed MA, Diener-West $M$ et al. Effect of weekly supplementations on incidence of pneumonia and diarrhea in children younger than 2 years in an urban, low income population in Bangladesh: Randomized controlled trial. The Lancet, 2005; 366: 999-1003.

14. Bangladesh Health \& Injury Survey (BHIS), Institute of Child \& Mother Health (ICMH), United Nation Children's Emergency Fund (UNICEF) \& The Alliance for Safe Children (TASC), 2005.

15. Arifeen SE, Akhter T, Chowdhury HR, Rahman KM, Chowdhury EK, Alam N, et al. Cause of death in children under 5 years of age. Bangladesh Demographic \& Health Survey (BDHS) 2004; 125-133.

16. Baqui $\mathrm{AH}$, et al. Effectiveness of $\mathrm{H}$ Influenzae type $\mathrm{B}$ conjugate vaccine on prevention of pneumonia and meningitis in Bangladeshi children. The Ped Inf Dis J 2007; 26(7): 565-571.

17. WHO. Weekly Epidemiol Rec, Bull of the World Health Organization 2007; 82: 93-104.

18. Fisherman SM. et al. Childhood \& maternal underweight. In:Ezzati MA, Lopez, A Rodgers A, et al. Comparative quantification of health risks: The global \& regional burden of disease attributable to selected major risk factors. Bull of the World Health Organization, Geneva 2004, (Cross ref from 1).

19. UNICEF. Immunization Plus. http://www.unicef.org/ immunization/index_measles.htlm> [accessed: Nov 2005].

20. Veirum J.E., et al. Routine vaccinations associated with divergent effects on female and male mortality at the pediatric ward in Bissau, Guinea Bissau. Vaccine 2005; 23 : 1197-1204 (Cross ref from 1).

21. Saha SK, Rikitomi N, Amin MR, Makasi H, Hanif M et al. Antimicrobial resistance \& serotype distribution of Streptococcus pneumoniae strains causing invasive childhood infections in Bangladesh, 1993 to 1997. J Clin Microbiol, Mar 1999; 37(3): 798-800.

22. UNICEF. Immunization: Hib. http://www.unicef.org/ immunization/23245_hib.htlm> [accessed: Nov 2005].

23. Felicity Cutts, et al. Vaccine Against Childhood Pneumonia Shows Promise Science Daily (Jun. 1, 2005). (Cross ref from 1).

24. WHO. Haemophilus influenzae type-b(Hib). http://www.who.int/ medicentre/factssheet/fs294/en/index.htm > [accessed: Nov 2005].

25. WHO. Weekly Epidemiol Rec Jan 6,2006; 81: 1-12; http:// www.who.int/immunization/conclusion_recommendations. pdf $>$ [accessed: Nov 2005].

26. Stephens S. Invasive Pnm \& Antibiotic Resistance Decreased After Childhood Vaccine Introduced. The Lancet, March 5, 2005. Science Daily (Apr 7, 2005). [accessed from the net "Science News" on 22 October 2007].

27. Hazir T, Qazi SA, Nisar Y B, et al. Comparison of Standard versus double dose of amoxycillin in the treatment of non severe pneumonia in children aged 2-59 months: a multicentre, double blinded, randomized controlled trial in Pakistan. Arch Dis Child 2007; 92: 291-297.

28. WHO. Weekly Epidemiol Rec 23 March 2007; 12(82): $93-$ 104. 